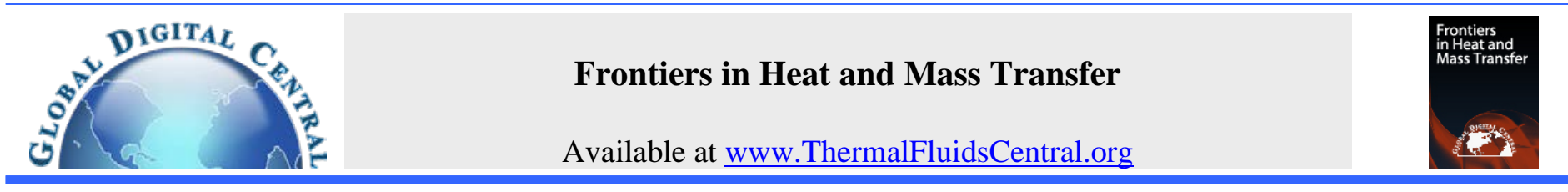

\title{
ANALYTICAL STUDY OF UNSTEADY SQUEEZED FLOW OF WATER BASE CNTS NANOFLUID WITH MAGNETIC FIELD AND VARIABLE THERMAL CONDUCTIVITY OVER A STRETCHING SURFACE
}

\author{
Ali Rehman ${ }^{\mathrm{a}}$, Zabidin Salleh ${ }^{\mathrm{a}, *}$, Taza Gul ${ }^{\mathrm{b}}$ \\ ${ }^{a}$ Department of Mathematics, Faculty of Ocean Engineering Technology and Informatics, Universiti Malaysia Terengganu, \\ 21030 Kuala Nerus, Terengganu, Malaysia \\ ${ }^{b}$ Department of Mathematics, City University of Science and Information Technology, Peshawar P/C, 25000, Pakistan.
}

\begin{abstract}
This research paper explains the analytical solution unsteady squeezing flow of water based CNTs for both MWCNT and SWCNT in the presence of magnetic field and variable thermal conductivity. The given partial differential equation is converted to nonlinear ordinary differential equation by using the similarity transformation and solve by analytical method namely optimal homotopy asymptotic method (OHAM) to obtain analytical solution of the nonlinear problem which analyze the problem. The result of important parameter for both velocity and temperature profiles are plotted and discussed. The BVPh 2.0 package is used to obtain the convergence of the problem up to 25 iteration. The skin friction coefficient and Nusselt number is explained in table form.
\end{abstract}

Keywords: Water based CNTs nanofluid, OHAM, squeezing flow, MHD, stretching surface.

\section{INTRODUCTION}

Due to the progress in fluid mechanics and its application in industrial, squeezing flow is interesting area for the researcher in the present time. The application of squeezing flow is polymer processing, food engineering, physical comparison, injection molding and biophysical. Kuzma et al. (1968) used squeezing films to discuss fluid inertia effect. Gupta and Gupta (1977) used parallel plate to discuss squeezing flow, the researchers (Wang and Watson, 1979; Bhattacharyya and Pal, 1997; $\mathrm{Xu}$ et al., 2010; Ganji et al., 2014) discussed heat transfer involving squeezing flow. There are some important applications of the analysis of heat transfer, for example, energy production, heat conduction in tissues, astro physical flow, missiles physical flow and electrical power generation. Grubka and Bobba (1985) used stretching surface to discuss heat transfer phenomena. Dutta (1988) used stretching surface to investigate the hydro magnetic flow and heat transfer. The researcher (Rudraswamy et al., 2017; Rudraswamy and Gireesha, 2014; Kuiry and Bahadur, 2015; Rudraswamy et al., 2016; Ganesh et al., 2017) discussed the effect of thermal radiation and heat transfer. Chaim (1998) used stretching sheet to discuss the impact of variable thermal conductivity and heat transfer. Sharma and Singh (2009) used linearly stretching sheet to discus MHD flow with variable thermal conductivity. Salahuddin et al. (2016) used Keller box method to investigate the effect of thermal conductivity and MHD flow, for this they use stretching cylinder. Malik et al. (2016) used stretching cylinder to investigate MHD flow of Sisko fluid.

The achievement of energy is not enough, but also to adjust the consumptions of energy and this is possible only to approve the development heat transmission liquids to mechanism the expenditures of energy and to improvement the most heat transmission which is the demand of the industry and other related scientific fields. Former to the application of nanotechnology, analysts and engineers have challenged such huge numbers of questions, recognizing with heat transmission fluids, still, with the development of nanometer sized particles and its uses in the heat transfer fluids have overall improved thermal conductivity. Rehman et al. (2019c) used stretching sheet to discuss the viscous dissipation of thin film unsteady flow of GO-EG/GO-W nanofluids. The most common lecture of carbon family is carbon nanotube (CNT). Carbon nanotube is used as a nanomaterial to rise heat transmission. Single wall carbon nanotube (SWCNT) and multi wall carbon nanotube (MWCNT) are two subclass of carbon nanotube (CNT). The key use of carbon nanotube (CNT) in engineering is for fluidization and heat conversation. Iijima was the first one to present carbon nanotube (CNT) in 1991 and also the first time present the multi wall carbon nanotube (MWCNT) by using Krastschmer and Huddman method, see (Iijima, 1991; Ajayan and Iijima, 1993). Donald Bethune in 1993 studied multiwall carbon nanotube (MWCNT). They discuss the diameter range of multiwall carbon nanotube and show that the diameter range of multiwall carbon nanotube is $0.4 \times 10^{-9} \mathrm{~m}$ to $3 \times 10^{-9} \mathrm{~m}$ (To, 2006). In multiwall carbon nanotube there are 2 to 50 coaxial nanotube with diameter range from $3 \times 10^{-9} \mathrm{~m}$ to $30 \times 10^{-9} \mathrm{~m}$ (Dresselhaus et al., 1995). Hone (2004) investigated that at room temperature the thermal conductivity of MWCNT is $3000 \mathrm{Wm}^{-1} \mathrm{~K}^{-1}$ and for SWCNT is $6600 \mathrm{Wm}^{-1} \mathrm{~K}^{-1}$. Haq et al. (2015) discussed the compression of engine base (CNT) and kerosene oil base (CNT) and show that the skin friction of water base (CNT) is greater than the kerosene oil base (CNT). Khan et al. (2014) used stretching plate to discuss the thermal conductivity and navier slip boundary condition for CNT. Kamali and Binesh (2010) used CNT base nanofluid to discuss the model of power law. Rehman et al. (2019a) used stretching cylinder to discuss Marangoni convection of thin film spray of CNT nanofluid. Rehman et al. (2019b) discussed the impact 
of magnetic field and viscous dissipation on the thin film unsteady flow of GO-EG/GO-W nanofluids.

Atashafrooz et al. (2020) investigated interacting infancies of Lorentz force and bleeding on the hydrothermal behaviors of nanofluid flow in a trapezoidal recess with help of second law of thermodynamics. Sheikholeslami (2019) used $\mathrm{Al}_{2} \mathrm{O}_{3}$ nanoparticles to discuss magnetic force and radiation influences by using permeable media. Sheikholeslami et al. (2014) investigated the influence of radiative heat transfer on thermal characteristics of nanofluid flow in the presence of magnetic field. Atashafrooz (2019) discussed the effect of buoyancy force on mixed convection heat transfer of MHD nanofluid flow and entropy generation in inclined duct by using Brownian motion. Sajjadi et al. (2019) used double MRT Lattice Boltzmann method to discuss the simulation of three dimensional MHD. Atashafrooz et al. (2019) investigated the interaction effects of an inclined magnetic field and nanofluid on forced convection heat transfer and flow irreversibility in a duct with and abrupt contraction. Sajjadi et al. (2018) investigated double MRT Lattice Boltzmann simulation of 3-D MHD natural convection in a cubic cavity with sinusoidal temperature distribution. Furthermore, Mahentesh and Shakunthala (2017) investigated the flow and heat transfer of carbon nanofluids over a vertical plate. Next, Astuti et al. (2019) studied the natural convection of nanofluids past an accelerated vertical plate with variable wall temperature in the presence of the radiation. Recently, Luay et al. (2019) studied the thermal and mechanical properties of fibre-glass multi-wall carbon nanotube/epoxy. They obtained several interesting results.

In this research paper, we explain the analytical solution of unsteady squeezing flow of water based CNTs for both MWCNT and SWCNT in the presence of magnetic field and variable thermal conductivity. The given partial differential equation is converted to nonlinear ordinary differential equation by using the similarity transformation and solve by analytical method, i.e., optimal homotopy asymptotic method (OHAM). Liao (2010) used this method for the solution of nonlinear problem and shows that this method is quickly convergent to the approximate solution. This method gives us series solution in the form of functions and all the physical parameters of the problem involved in this method. The result of important parameter for both velocity and temperature profiles are plotted and discussed.

\section{MATHEMATICAL FORMULATION}

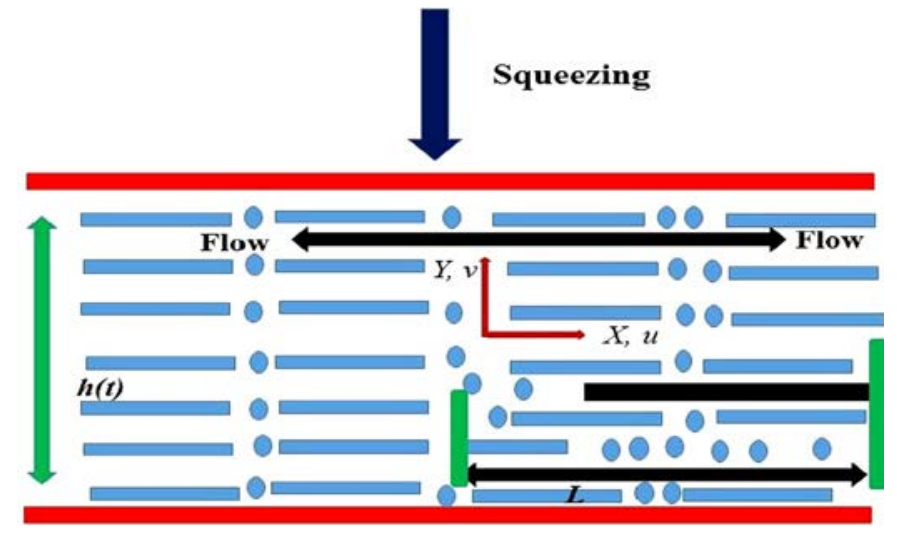

Fig. 1 Geometry of the problem.

Consider the unsteady boundary layer flow of water base CNTs. Figure 1 shows the closed squeezed channel with height $h(t)$, supposed that $h(t)$ is greater than that boundary layer thickness. $L$ represent micro cantilever of length which is enclosed inside the channel. It is supposed that the squeezing stream is to be occurred from the tip to the surface. Moreover it is assumed that lower plat is in rest. The continuity and momentum equations are settled, see (Kumar et al., 2017):

$$
\begin{gathered}
\frac{\partial u}{\partial x}+\frac{\partial v}{\partial y}=0 \\
\frac{\partial u}{\partial t}+u \frac{\partial u}{\partial x}+v \frac{\partial u}{\partial y}=-\frac{1}{p} \frac{\partial p}{\partial x}+v(1-n) \frac{\partial^{2} u}{\partial y^{2}}+\sqrt{2} v n \Gamma\left(\frac{\partial u}{\partial y}\right) \frac{\partial^{2} u}{\partial y^{2}} \\
-\frac{\sigma B_{0}^{2}}{\rho} u \\
\frac{\partial U}{\partial t}+U \frac{\partial U}{\partial x}=-\frac{1}{\rho}\left(\frac{\partial p}{\partial x}\right)-\frac{\sigma B_{0}^{2}}{\rho} U \\
\frac{\partial T}{\partial t}+u \frac{\partial T}{\partial x}+v \frac{\partial T}{\partial y}=\frac{\partial}{\partial y}\left(x(t) \frac{\partial T}{\partial y}\right)
\end{gathered}
$$

Here $u$ and $v$ are the velocity component with $x$ and $y$ direction. Kinematic viscosity is denoted by $v$, the stream velocity is denoted by $U$, the variable thermal conductivity is denoted by $\alpha$, the power law index is denoted by $n$, the time constant is denoted by $C$, the electric charge density is denoted by $\rho$, the fluid pressure is denoted by $p$, and the temperature is denoted by $T$. By eliminating the pressure term from equation (2) and equation (3), we obtain

$$
\begin{aligned}
\frac{\partial u}{\partial t}+u \frac{\partial u}{\partial x}+v \frac{\partial u}{\partial y} & =\frac{\partial U}{\partial t}+U \frac{\partial U}{\partial x}+v(1-n) \frac{\partial^{2} u}{\partial y^{2}}+\sqrt{2} v n \Gamma\left(\frac{\partial u}{\partial y}\right) \frac{\partial^{2} u}{\partial y^{2}} \\
& +\frac{\sigma B_{0}^{2}}{\rho}(U-u)
\end{aligned}
$$

with boundary condition

$$
\begin{gathered}
u(x, 0, t), v(x, 0, t)=-v_{0}(t),-k \frac{\partial T(x, 0, t)}{\partial y}=q(x) \\
u(x, \infty, t)=U(x, t), T(x, \infty, t)=T_{\infty} .
\end{gathered}
$$

The free stream temperature wall heat flux and free stream velocity is denoted by $T_{\infty}, U(x, t)$ and $q(x), \alpha=\alpha_{\infty}(1+\varepsilon \theta)$ represent the thermal conductivity. The similarity transformation is defined as

$$
\begin{gathered}
U=a x, \psi=x \sqrt{a v} f(\eta) \cdot a=\frac{1}{s+b t}, u=a x f^{\prime}(\eta) \\
v=-f(\eta) \sqrt{a v}, \theta(\eta)=\frac{T-T_{\infty}}{q_{0} x \sqrt{\frac{v}{a}}}, \eta=y \sqrt{\frac{a}{v}}
\end{gathered}
$$

where $b$ is the squeezed flow index, $s$ is arbitrary constant, $a$ show strength squeezing flow parameter, heat flux is represented by $q_{0}$ and $k$ is the thermal conductivity. Using the similarity transformation in equation (4) and equation (5) the partial differential equation is transform to ordinarily differential equation:

$$
\begin{aligned}
f^{\prime \prime \prime}+(1-\phi)^{2.5}\left(1-\phi+\phi \frac{\left(\rho_{s}\right)_{C N T}}{\left(\rho_{f}\right)_{C N T}}\right)\left(f+\frac{b \eta}{2}\right) f^{\prime \prime \prime}-\left(f^{\prime}\right)^{2} & \\
& +b\left(f^{\prime}-1\right)+n w_{e} f^{\prime \prime 2}(\eta) f^{\prime \prime \prime}(\eta) \\
& -M(1-\phi)^{2.5}\left(1-f^{\prime}\right) \\
& =0 \\
\frac{k_{n f}}{k_{f}} \theta^{\prime \prime}+ & \operatorname{Pr}\left[(1-\phi)+\phi \frac{\left(\rho c_{p}\right)_{C N T}}{\left(\rho c_{p}\right)_{C N T}}\right]\left(f+\frac{b \eta}{2}\right) \theta^{\prime}+\operatorname{Pr\varepsilon }\left(\theta^{\prime}\right)^{2} \\
& -\operatorname{Pr}\left(f^{\prime}+\frac{b}{2}\right) \theta=0
\end{aligned}
$$




$$
\begin{gathered}
f(0)=-f_{0}, f^{\prime}(0)=0, \theta^{\prime}(0)=-1 \\
f^{\prime}(\infty) \rightarrow 1, \theta(\infty) \rightarrow 0
\end{gathered}
$$

where $\operatorname{Pr}=\frac{v}{\sigma}$ is Prandtl number, $f_{0}=\sqrt{v}$ is permeable velocity, $w_{e}=$ $\frac{\sqrt{2 a} \Gamma U}{\sqrt{v}}$ and $M=\frac{\sigma B_{0}^{2}}{\sigma a}$ is magnetic parameter and $n$ is the power law index. The coefficient of skin friction and Nusselt number is defined as

$$
\begin{gathered}
\sqrt{R e_{x}} C_{f}=\left[(1-n) f^{\prime \prime}(\eta)+\frac{n}{2} w_{e}\left(f^{\prime \prime}(\eta)\right)^{2}\right]_{\eta=0} \text { and } \quad N u_{x} \sqrt{R e_{x}} \\
=-\theta^{\prime}(\eta)_{\eta=0} .
\end{gathered}
$$

\section{Method of Solution}

The analytical method (OHAM) is used to find the approximate analytical solution of the nonlinear ordinary differential equation. The BVPh 2.0 package function of Mathematica is used to obtain the numerical results, the result of important parameters. The given equations (7) and (8) are solved analytically by analytical method, i.e., optimal homotopy asymptotic method (OHAM) which is given below

$$
L(u(x))+N(u(x))+g(x)=0, B(u(x))
$$

where $L$ is linear operator, $x$ is independent variable, $g(x)$ is the unknown function, $N$ is the nonlinear operator and $B(u)$ is a boundary operator. By using this method, we first find a family of equations

$$
\begin{gathered}
H(\phi(x), p)=(1-p)[L(\phi(x, p))+g(x)] \\
-H(p)[L(\phi(x, p))+g(x)+N(\phi(x, p))]=0 \\
B(\phi(x, p))=0
\end{gathered}
$$

where $p$ is an embedding or inserting parameter and lies in $[0,1], H(p)$ is the nonzero auxiliary function for $p \neq 0$ and $H(0)=0$ and $\phi(x, p)$ is an unknown function. Using the initial guessed values and auxiliary linear operators from equations (8-9)

$$
\begin{gathered}
f_{0}(\eta)=\frac{(b-m)}{24} \eta^{4}+\frac{c_{2} \eta^{2}}{2}-f_{0}=0 \\
L_{f}=\frac{d^{4} f}{d \eta^{4}}, L_{\theta}=\frac{d^{2} \theta}{d \eta^{2}} .
\end{gathered}
$$

When $p=0$, equation (11) become as

$$
L(\phi(x, p))+g(x)=0 .
$$

Let the solution of equation (14) be

$$
v_{0}(x)
$$

When $p=1$, equation (14) become as

$$
L(\phi(x, p))+g(x)+N(\phi(x, p))=0,
$$

which has a solution, let the solution is

$$
v(x)
$$

Thus by increasing $p$ from 0 to 1 , the solution change form $v_{0}(x)$ to $v(x)$. Choose the supplementary function as

$$
H(P)=P C_{1}+P^{2} C_{2}+P^{3} C_{3}+\cdots
$$

where $C_{1}, C_{2}, C_{3}, \ldots$ are constants to be determined. Expanding $\phi(x, p)$ in a series with respect to $p$, we have

$$
\phi\left(x, p, C_{i}\right)=v_{0}(x)+\sum_{k=1}^{\infty} v_{k}\left(x, C_{i}\right) p^{k}
$$

for $=1,2,3 \ldots$. Put equation (19) into equation (11) and comparing the coefficient of different power of $p$, we get differential equations with boundary condition. By solving this equation, we find a series solution in the form of functions $v_{0}(x), v_{1}\left(x, C_{1}\right), v_{2}\left(x, C_{2}\right), \ldots$ and the solution of equation (10) can be written as

$$
v\left(x, C_{i}\right)=v_{0}(x)+\sum_{k=1}^{\infty} v_{k}\left(x, C_{i}\right)
$$

The residual is as follow

$$
R\left(x, C_{i}\right)=L\left(v\left(x, C_{i}\right)\right)+N\left(v\left(x, C_{i}\right)\right)+g(x) .
$$

If in equation (21), $\left(x, C_{i}\right)=0$, then equation (20) has exact solution but for nonlinear differential equation is not possible. We try to minimize the $R\left(x, C_{i}\right)$ to get the best approximate analytical solution of equation (10).

\section{RESULTS AND DISCUSSION}

Table 1 Comparison of the skin friction for the two nanofluids when $\operatorname{Pr}=5.6, w_{e}=0.1, \varepsilon=1$.

\begin{tabular}{|c|c|c|c|}
\hline $\boldsymbol{b}$ & $\boldsymbol{M}$ & MWCNT & SWCNT \\
\hline 0.1 & 0.2 & 0.729705 & 0.99471 \\
\hline 0.3 & & 0.72164 & 0.979547 \\
\hline 0.5 & & 0.71147 & 0.97264 \\
\hline & 0.4 & 0.7100877 & 0.96994 \\
\hline & 0.6 & 0.70608 & 0.93724 \\
\hline & & 0.698432 & 0.9246 \\
\hline & & 0.65818 & 0.91641 \\
\hline
\end{tabular}

Table 2 Comparison of the Nusselt number $\left(R e_{x}^{-\frac{1}{2}} N u_{x}\right)$ for the two nanofluids when $f_{0}=0.1, M=0.2, b=0.5$.

\begin{tabular}{|c|c|c|c|}
\hline $\boldsymbol{P r}$ & $\boldsymbol{w}_{\boldsymbol{e}}$ & MWCNT & SWCNT \\
\hline 1.5 & 0.1 & 0.61231 & 0.49077 \\
\hline 2.5 & & 0.59341 & 0.48237 \\
\hline 3.5 & & 0.57451 & 0.47397 \\
\hline & 0.2 & 0.55614 & 0.45647 \\
\hline & 0.3 & 0.53776 & 0.44897 \\
\hline & & 0.52795 & 0.43121 \\
\hline & & 0.55021 & 0.41346 \\
\hline
\end{tabular}

Table 3 Convergence of the method for SWCNT when $\operatorname{Pr}=6.7$, $M=0.1, f_{0}=0.1, \phi=0.01, \varepsilon=1$.

\begin{tabular}{|c|c|c|}
\hline $\boldsymbol{m}$ & $\boldsymbol{\varepsilon}_{\boldsymbol{m}}^{\boldsymbol{f}}$ SWCNT & $\boldsymbol{\varepsilon}_{\boldsymbol{m}}^{\boldsymbol{\theta}}$ SWCNT \\
\hline 5 & $1.55438 \times 10^{-1}$ & $2.86775 \times 10^{-1}$ \\
\hline 10 & $7.69094 \times 10^{-3}$ & $1.48738 \times 10^{-2}$ \\
\hline 15 & $2.209443 \times 10^{-7}$ & $1.07298 \times 10^{-4}$ \\
\hline 20 & $3.37298 \times 10^{-9}$ & $8.54131 \times 10^{-5}$ \\
\hline 25 & $3.33787 \times 10^{-11}$ & $7.94423 \times 10^{-6}$ \\
\hline
\end{tabular}


Table 4 The convergence of method for MWCNT when $\operatorname{Pr}=6.7$, $M=0.1, w_{e}=0.1, \phi=0.01, \varepsilon=1$.

\begin{tabular}{|c|c|c|}
\hline $\boldsymbol{m}$ & $\boldsymbol{\varepsilon}_{\boldsymbol{m}}^{\boldsymbol{f}}$ MWCNT & $\boldsymbol{\varepsilon}_{\boldsymbol{m}}^{\boldsymbol{\theta}}$ MWCNT \\
\hline 5 & $1.07991 \times 10^{-1}$ & $2.88574 \times 10^{-1}$ \\
\hline 10 & $5.65266 \times 10^{-2}$ & $1.0759 \times 10^{-3}$ \\
\hline 15 & $4.12383 \times 10^{-3}$ & $1.0759 \times 10^{-5}$ \\
\hline 20 & $3.4616 \times 10^{-4}$ & $8.55721 \times 10^{-7}$ \\
\hline 25 & $3.133 \times 10^{-5}$ & $8.006632 \times 10^{-9}$ \\
\hline
\end{tabular}

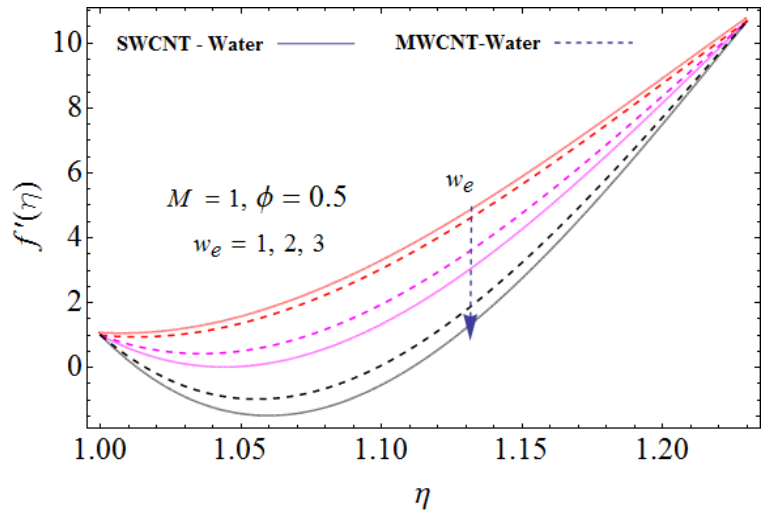

Fig. 2 Effect of Weissenberg number on velocity profile.

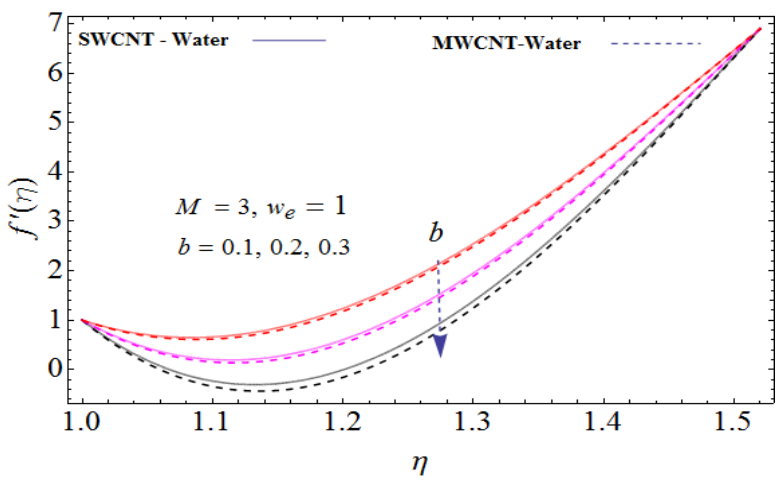

Fig. 3 Effect of squeezed flow index on velocity profile.

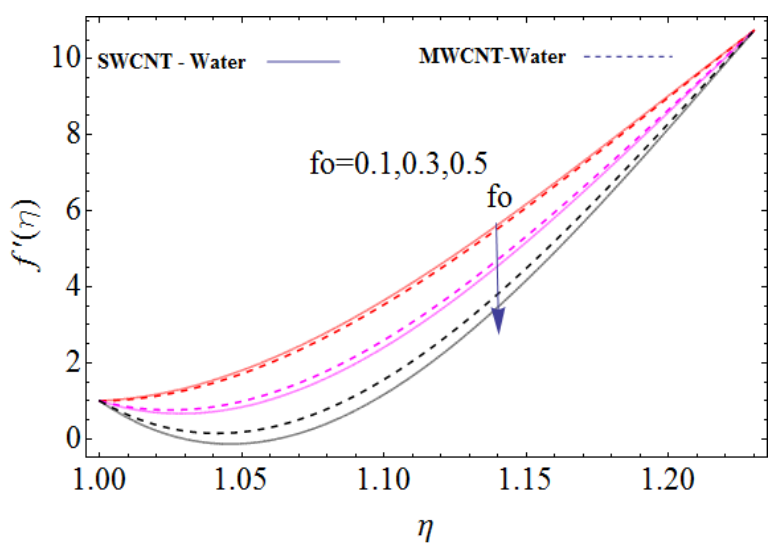

Fig. 4 Effect of permeable velocity on velocity profile.

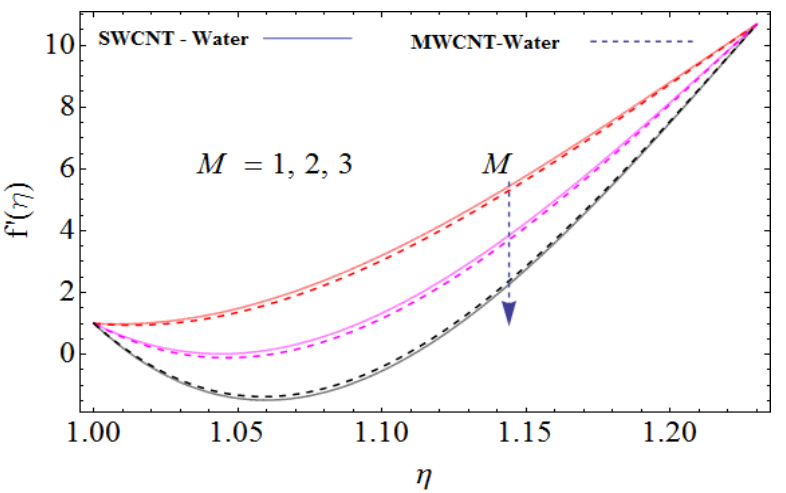

Fig. 5 Effect of magnetic parameter on velocity profile.

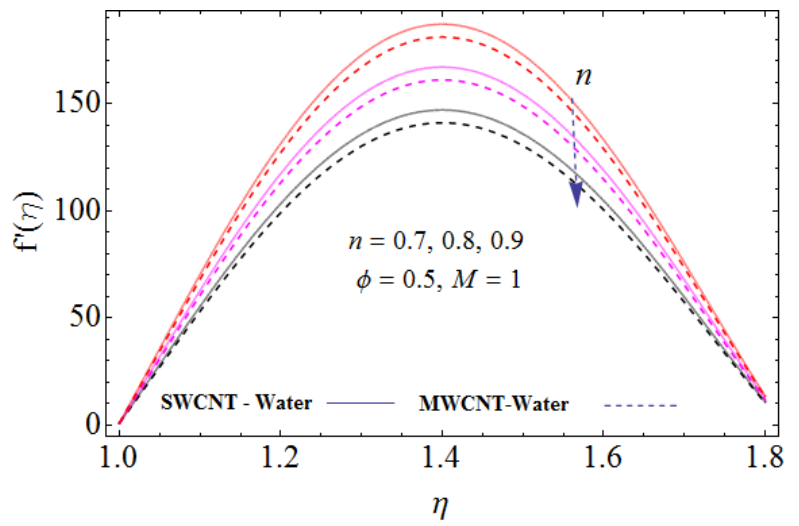

Fig. 6 Effect of power law index on velocity profile.

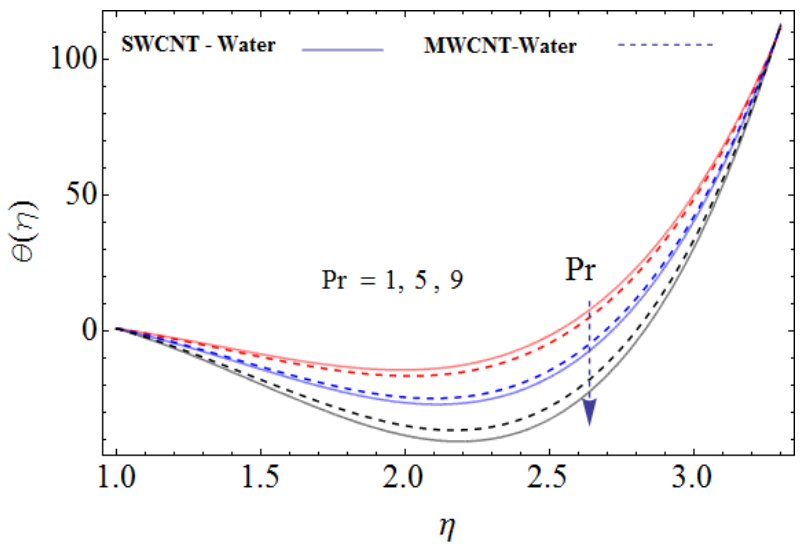

Fig. 7 Effect of Prandtl number on temperature profile.

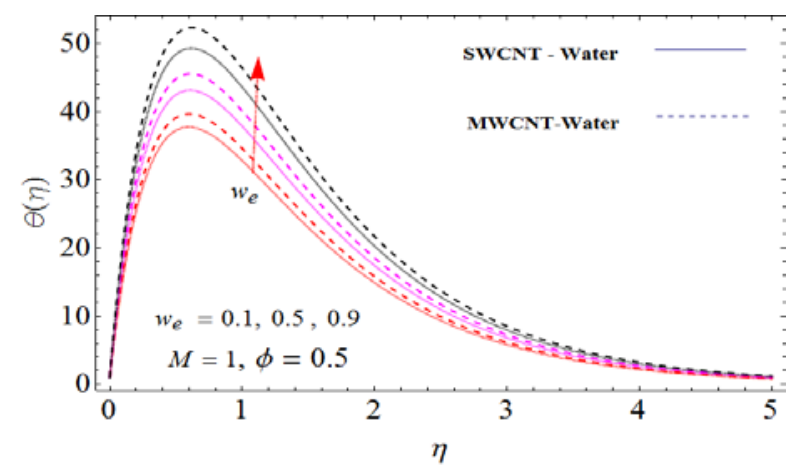

Fig. 8 Effect of Weissenberg number on temperature profile. 


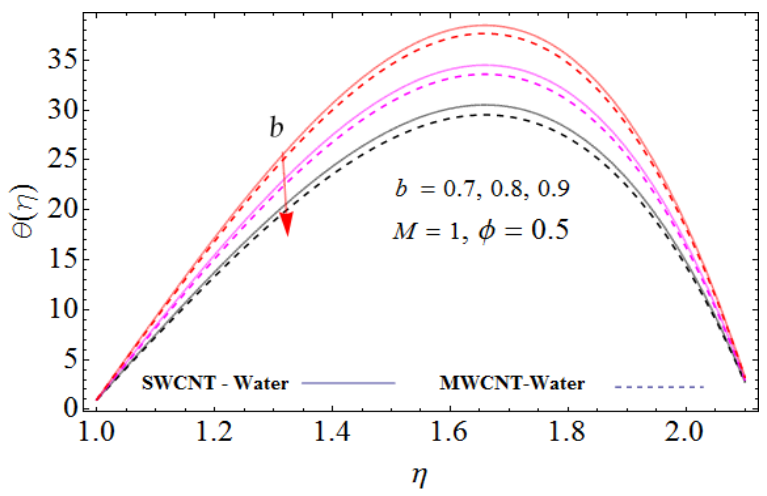

Fig. 9 Effect of squeezed flow index on temperature profile.

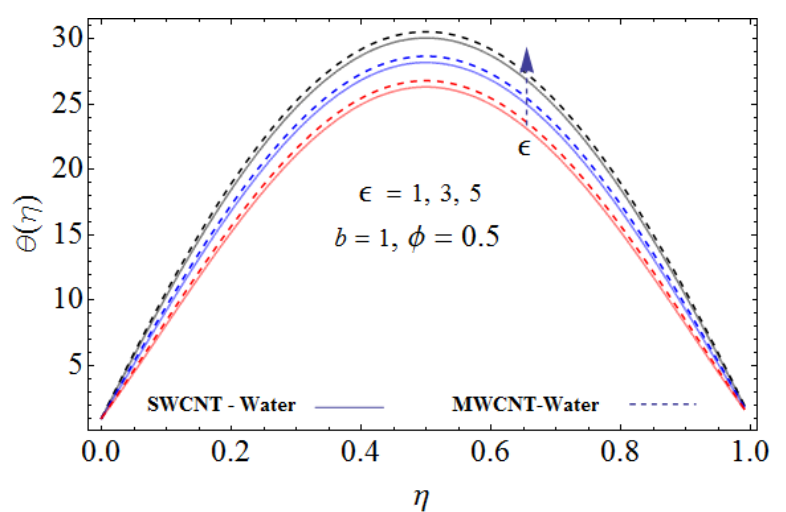

Fig. 10 Effect of $\varepsilon$ on temperature profile.

The main objective of this section is to study the effect of various model factors like $M, f_{0}, \operatorname{Pr}, w_{e}, \varepsilon, n, b$ (magnetic parameter, permeable velocity, Prandtl number, Weissenberg number, small quantity, power law index and squeezed flow index on velocity and temperature distribution). In Tables 1 and 2, the numeric results illustrate the impacts of different model factors on the skin friction coefficient and Nusselt number of both MWCNT and SWCNT. The effect of different parameters on local skin friction coefficient is shown in Table 1. The Table 1 depicts that skin friction coefficient decreasing in both MWCNT and SWCNT for the increasing value of squeezed flow index and magnetic field. Whereas, Table 2 shows the Nusselt number coefficient decreasing in both MWCNT and SWCNT for the increasing value of Prandtl number and Weissenberg number. The convergence for both MWCNT and SWCNT nanofluid has been obtained up to the $25^{\text {th }}$ iteration for the SWCNT and MWCNT nanofluid in Tables 3 and 4 oneto-one. The Tables 3 and 4 show that by increasing the number of iteration reduces the order of residual error and strong convergence attained.

Fig. 2 shows the effect of Weissenberg number on velocity profile. The relation between Weissenberg number and velocity is inverse relation, by increasing Weissenberg number the velocity profile decreasing. By increasing the Weissenberg number, increase the relaxation time of fluid due to the resistance produced in the flow direction and as a result velocity profile is decreasing as shown in Fig. 2. Fig. 3 shows the effect of squeezed flow index on velocity profile. The relation between squeezed flow index and velocity is inversely relation. By increasing squeezed flow index, the velocity profile decreasing because by increasing squeezing phenomena, the kinetic energy of the fluid particle increase but there is inverse relation between strength of squeeze flow and squeezed flow index. So as a result velocity profile decrease as shown in Fig. 3. Fig. 4 shows the effect of permeable velocity on velocity profile. The relation between permeable velocity and velocity is inversely relation. The velocity profile decreasing by increasing the permeable velocity because by increasing permeable velocity suction is produced and due to this fluid to be more attached to surface.

Fig. 5 shows the effect of magnetic parameter on velocity profile. The relation between magnetic parameter and velocity is inversely relation. By increasing magnetic parameter the velocity profile decreasing because by increasing the magnetic parameter, resistance in the flow direction increasing due to which velocity profile decreasing as shown in Fig. 5. Fig. 6 shows the effect of power law index on velocity profile, the relation between power law index and velocity is inversely relation. By increasing power law index the velocity profile decreasing because by increasing the power law index will reduce the fluid motion. So as a result velocity profile decreasing as shown in Fig. 6. Fig. 7 shows the effect of the $\operatorname{Pr}$ against the $\theta(\eta)$ temperature field. The relation between temperature field and $P r$ is inverse relation, so by enhance the $\operatorname{Pr}$ decreasing the temperature profile as displayed in Fig. 7. In fact, the thickness of the momentum boundary layer to be larger than that of the thermal boundary layer, or that the viscous diffusion is larger than the thermal diffusion and therefore, the larger amount of the $\operatorname{Pr}$ reduces the thermal boundary layer.

Fig. 8 shows the effect of Weissenberg number on temperature profile. The relation between Weissenberg number and temperature is direct relation. By increasing Weissenberg number the temperature profile increasing. By increasing Weissenberg number the thermal boundary layer decreasing, so as a result the temperature profile increasing. Fig. 9 shows the effect of squeezed flow index on temperature profile. The relation between squeezed flow index and temperature is inversely relation. By increasing squeezed flow index the temperature profile decreasing because by increasing squeezed flow index the thickness of the momentum boundary layer to be larger than that of the thermal boundary layer, so as result temperature profile decreasing. Fig. 10 shows the effect of $\varepsilon$ on temperature profile. The relation between $\varepsilon$ and temperature is direct relation. By increasing $\varepsilon$ the temperature profile increasing because by increasing the small partial, increase the kinetic energy of the fluid particle which increase the variation of thermal characteristics, so as a result the temperature profile increase.

\section{CONCLUSIONS}

This paper explained the unsteady squeezing flow of water based nanofluid CNTs for both MWCNT and SWCNT in the presence of magnetic field and variable thermal conductivity. The model is solved by analytical method namely optimal homotopy asymptotic method (OHAM) to obtain analytical solution of the nonlinear problem which analyze the problem. The result of important parameter for both velocity and temperature profiles are plotted and discussed. The skin friction coefficient and Nusselt number is explained in table form. The obtained outputs are deliberated as follows. It is observed that:

- Increasing Weissenberg number, decreasing the velocity field.

- Increasing the squeezed flow index, decreasing the velocity profile.

- Increasing the values of the magnetic field, decreasing the velocity profile.

- By increasing the Prandtl number Pr, decreasing the temperature profile.

- By increasing the $\varepsilon$, increasing the temperature field.

\section{ACKNOWLEDGEMENTS}

This research has been partially supported by Universiti Malaysia Terengganu under the Postgraduate Research Grant (PGRG) vote no. 55193/3. 


\section{REFERENCES}

Astuti, H., Sri, P., and Kaprawi, S., 2019, "Natural Convection of Nanofluids Past an Accelerated Vertical Plate with Variable Wall Temperature by Presence of the Radiation," Frontiers in Heat and Mass Transfer, 13, 3.

http://dx.doi.org/10.5098/hmt.13.3

Ajayan, P.M., and Iijima, S., 1993, "Capillarity-Induced Filling of Carbon Nanotubes,” Nature, 361, 333-334.

https://doi.org/10.1038/361333a0

Atashafrooz, M., 2019, “The Effects of Buoyancy Force on Mixed Convection Heat Transfer of MHD Nanofluid Flow and Entropy Generation in an Inclined Duct with Separation Considering Brownian Motion Effects," Journal of Thermal Analysis and Calorimetry, 138(5), 3109-3126.

https://doi.org/10.1007/s10973-019-08363-w

Atashafrooz, M., Sajjadi, H., and Delouei, A.A., 2020, "Interacting Influences of Lorentz Force and Bleeding on the Hydrothermal Behaviors of Nanofluid Flow in a Trapezoidal Recess with the Second Law of Thermodynamics Analysis," International Communications in Heat and Mass Transfer, 110, 104411.

https://doi.org/10.1016/j.icheatmasstransfer.2019.104411

Atashafrooz, M., Sheikholeslami, M., Sajjadi, H., and Delouei, A.A., 2019, "Interaction Effects of an Inclined Magnetic Field and Nanofluid on Forced Convection Heat Transfer and Flow Irreversibility in a Duct with an Abrupt Contraction," Journal of Magnetism and Magnetic Materials, 478, 216-226.

https://doi.org/10.1016/j.jmmm.2019.01.111

Bhattacharyya, S., and Pal, A., 1997, "Unsteady MHD Squeezing Flow between Two Parallel Rotating Discs,” Mech Res Common, 24(6), 615623.

https://doi.org/10.1016/S0093-6413(97)00079-7

Chaim, T.C., 1998, "Heat Transfer in a Fluid with Variable Thermal Conductivity over Stretching Sheet," Acta Mechanica, 129(1-2), 63-72.

https://doi.org/10.1007/BF01379650

Dutta, B.K., 1988, "Heat Transfer from a Stretching Sheet in Hydromagnetic Flow,” Wärme-und Stoffübertragung, 23(1), 35-37.

https://doi.org/10.1007/BF01460746

Dresselhaus, M.S., Dresselhaus, G., and Saito, R., 1995, "Physics of Carbon Nanotubes," Carbon, 33(7), 883-891.

https://doi.org/10.1016/0008-6223(95)00017-8

Ganesh, Kumar K., Rudraswamy, N.G., Gireesha, B.J., and Krishnamurthy, M.R., 2017, "Influence of Nonlinear Thermal Radiation and Viscous Dissipation on Three-Dimensional Flow of Jeffrey Nanofluid over a Stretching Sheet in the Presence of Joule Heating,” Nonlinear Engineering, 6(3), 207-219.

http://dx.doi.org/10.1515/nleng-2017-0014

Ganji, D.D., Abbasi, M., Rahimi, J., Gholami, M., and Rahimipetroudi, I., 2014, "On the MHD Squeeze Flow between Two Parallel Disks with Suction or Injection via HAM and HPM," Frontiers of Mechanical Engineering, 9(3), 270-280.

https://doi.org/10.1007/s11465-014-0303-0

Grubka. L.J., and Bobba, K.M., 1985, "Heat Transfer Characteristics of a Continuous, Stretching Surface with Variable Temperature,” Journal of Heat Transfer, 107(1), 248-250.

https://doi.org/10.1115/1.3247387

Gupta, P.S. and Gupta A.S., 1977, "Squeezing Flow between Parallel Plates,” Wear, 45(2), 177-185. https://doi.org/10.1016/0043-1648(77)90072-2

Haq, R.U., Nadeem, S., Khan, Z.H., and Noor, N.F.M., 2015, "Convective Heat Transfer in MHD Slip Flow over a Stretching Surface in the Presence of Carbon Nanotubes,” Phys. B Condens. Matter, 457, 40-47.

https://doi.org/10.1016/j.physb.2014.09.031

Hone, J., 2004, “Carbon Nanotubes: Thermal Properties,” Dekker Encycl Nanosci Nanotechnol, 7, 603-610.

https://doi.org/10.1081/e-enn3-120009128

Iijima, S., 1991, “Helical microtubules of graphitic carbon,” Nature, 354, 56-58.

https://doi.org/10.1038/354056a0

Kamali, R., and Binesh, A.R., 2010, "Numerical Investigation of Heat Transfer Enhancement using Carbon Nanotube-Based Non-Newtonian Nanofluids," International Communications in Heat and Mass Transfer, 37, 1153-1157.

https://doi.org/10.1016/j.icheatmasstransfer.2010.06.001

Khan, W.A., Khan, Z.H., and Rahi, M., 2014, "Fluid Flow and Heat Transfer of Carbon Nanotubes along a Flat Plate with Navier Slip Boundary,” Applied Nanosciences, 4, 633-641. https://doi.org/10.1007/s13204-013-0242-9

Kuiry, D.R., and Bahadur, S., 2015, "Steady MHD Flow of Viscous Fluid between two Parallel Porous Plates with Heat Transfer in an Inclined Magnetic Field," Journal of Scientific Research, 7(3), 21-31. https://doi.org/10.3329/jsr.v7i3.22574

Kumar, K.G., Gireesha, B.J., Krishanamurthy, M.R., and Rudraswamy, N.G., 2017, “An Unsteady Squeezed Flow of a Tangent Hyperbolic Fluid over a Sensor Surface in the Presence of Variable Thermal Conductivity,” Results in Physics, 7, 3031-3036.

https://doi.org/10.1016/j.rinp.2017.08.021

Kuzma, D.C., 1968, “Fluid Inertia Effects in Squeeze Films,” Applied Scientific Research, 18, 15-20.

https://doi.org/10.1007/BF00382330

Liao, S.J., 2010, “An Optimal Homotopy-Analysis Approach for Strongly Nonlinear Differential Equations," Communications in Nonlinear Science and Numerical Simulation, 15, 2003-2016. https://doi.org/10.1016/j.cnsns.2009.09.002

Luay, H.A., Hyder, H.B., Ammar, F.A., and Zaid, S.K., 2019, “Study of Thermal and Mechanical Properties of Fibre-Glass Multi-Wall Carbon Nanotube/Epoxy," Frontiers in Heat and Mass Transfer, 13, 30. http://dx.doi.org/10.5098/hmt.13.30

Mahentesh, M.N., and Shakunthala, S., 2017, "Flow and Heat Transfer of Carbon Nanofluids over a Verticle Plate," Frontiers in Heat and Mass Transfer, 9, 27.

http://dx.doi.org/10.5098/hmt.9.27

Malik, M.Y., Hussain, A., Salahuddin, T., Awais, M., and Bilal, S., 2016, "Magnetohydrodynamic Flow of Sisko Fluid over a Stretching Cylinder with Variable Thermal Conductivity, a Numerical Study," AIP Advances, 6(2), 025316 .

https://doi.org/10.1063/1.4942476

Rehman, A., Gul, T., Salleh, Z., Mukhtar, S., Hussain, F., Nisar, K.S., and Kumam, P., 2019a, "Effect of the Marangoni Convection in the Unsteady Thin Film Spray of CNT Nanofluids,” Processes, 7, 392. https://doi.org/10.3390/pr7060392

Rehman, A., Salleh, Z., and Gul, T., 2019b, “The Impact of the Magnetic Field and Viscous Dissipation on the Thin Film Unsteady Flow of GO- 
EG/GO-W Nanofluids,” Journal of Physics: Conference Series, Vol. 1366, No. 1, p. 012031, IOP Publishing.

https://doi.org/10.1088/1742-6596/1366/1/012031

Rehman, A., Salleh, Z., Gul, T., and Zaheer, Z., 2019c, “The Impact of Viscous Dissipation on the Thin Film Unsteady Flow of GO-EG/GO-W Nanofluids," Mathematics, 7, 653.

https://doi.org/10.3390/math7070653

Rudraswamy, N.G., Ganesh, Kumar K., Gireesha, B.J., and Gorla, R.S.R., 2016, "Soret and Dufour Effects in ThreeDimensional Flow of Jeffery Nanofluid in the Presence of Nonlinear Thermal Radiation," Journal of Nanoengineering and Nanomanufacturing, 6(4), 278-287.

https://doi.org/10.1166/jnan.2016.1293

Rudraswamy, N.G., Ganesh, Kumar K, Gireesha, B.J., and Gorla, R.S.R., 2017, "Combined Effect of Joule Heating and Viscous Dissipation on MHD Three Dimensional Flow of a Jeffrey Nanofluid,” Journal of Nanofluids, 6(2), 300-310.

https://doi.org/10.1166/jon.2017.1329

Rudraswamy, N.G., and Gireesha, B.J., 2014, "Influence of Chemical Reaction and Thermal Radiation on MHD Boundary Layer Flow and Heat Transfer of a Nanofluid over an Exponentially Stretching Sheet," Journal of Applied Mathematics and Physics, 2(2), Article ID: 42204, 9 pages. https://doi.org/10.4236/jamp.2014.22004

Sajjadi, H., Delouei, A.A., Atashafrooz, M., and Sheikholeslami, M.J.I. J.O.H., 2018, “Double MRT Lattice Boltzmann Simulation of 3-D MHD Natural Convection in a Cubic Cavity with Sinusoidal Temperature Distribution Utilizing Nanofluid," International Journal of Heat and Mass Transfer, 126, 489-503.

https://doi.org/10.1016/j.ijheatmasstransfer.2018.05.064

Sajjadi, H., Delouei, A.A., Sheikholeslami, M., Atashafrooz, M., and Succi, S., 2019, "Simulation of Three Dimensional MHD Natural Convection using Double MRT Lattice Boltzmann Method,” Physica A: Statistical Mechanics and its Applications, 515, 474-496. https://doi.org/10.1016/j.physa.2018.09.164

Salahuddin, T., Malik, M.Y., Hussain, A., Bilal, S., and Awais, M., 2016, "Combined Effects of Variable Thermal Conductivity and MHD Flow on Pseudoplastic Fluid over a Stretching Cylinder by using Keller Box Method," Information Sciences Letters, 5(1), 11-19. doi:10.18576/isl/050102

Sharma, P.R., and Singh, G., 2009, "Effects of Variable Thermal Conductivity and Heat Source / Sink on MHD Flow near a Stagnation Point on a Linearly Stretching Sheet," Journal of Applied Fluid Mechanics, 2(1), 13-21. DOI: $10.36884 / j a f m .2 .01 .11851$

Sheikholeslami, M., 2019, "Numerical Approach for $\mathrm{MHD} \mathrm{Al}_{2} \mathrm{O}_{3}$-Water Nanofluid Transportation inside a Permeable Medium using Innovative Computer Method," Computer Methods in Applied Mechanics and Engineering, 344, 306-318. https://doi.org/10.1016/j.cma.2018.09.042

Sheikholeslami, M., Gorji-Bandpy, M., and Ganji, D.D., 2014, "Investigation of Nanofluid Flow and Heat Transfer in Presence of Magnetic Field using KKL Model,” Arabian Journal for Science and Engineering, 39(6), 5007-5016.

https://doi.org/10.1007/s13369-014-1060-4

To, C.W.S., 2006, "Bending and Shear Moduli of Single-Walled Carbon Nanotubes,” Finite Elements Analysis and Design, 42(5), 404-413. https://doi.org/10.1016/j.finel.2005.08.004

Wang, C.Y., and Watson, L.T., 1979, "Squeezing of a Viscous Fluid between Elliptic Plates,” Applied Scientific Research, 35, 195-207. https://doi.org/10.1007/BF00382705

Xu, C., Yuan, L., Xu, Y., and Hang, W., 2010, "Squeeze Flow of Interstitial Herschel-Bulkley Fluid between Worigid Spheres," Particuology, 8, 360-364.

https://doi.org/10.1016/j.partic.2009.07.008 